\title{
TRATAMENTO DOS RESÍDUOS GERADOS NA SÍNTESE DE POLIANILINA EM ESCALA PRÉ-PILOTO
}

\author{
Rafael Arromba de Sousa, Olacir Alves Araújo, Patrícia S. de Freitas e Marco-A. De Paoli* \\ Instituto de Química, Universidade Estadual de Campinas, CP 6154, 13084-971 Campinas - SP
}

Recebido em 6/1/03; aceito em 29/4/03

\begin{abstract}
TREATMENT OF THE RESIDUES GENERATED BY POLYANILINE SYNTHESIS IN PRE-PILOT SCALE. Polyaniline (PAni) is one of the most studied conducting polymer. It can be synthesized by two methods: electrochemical or chemical oxidation. The chemical oxidation is more adequate to produce large quantities of polymer. Regardless of the synthesis scale, the treatment of the residues before its final destination is very important and necessary because it contains toxic aniline derivatives (carcinogens in some cases), acids and inorganic salts, both with low toxicity. In this work we discuss the methods used to treat these residues and to eliminate and discard the toxic substances. These were extracted from the reaction residues by using activated coal and the $\mathrm{pH}$ of the residue was neutralized.
\end{abstract}

Keywords: polyaniline; residues; coal.

\section{INTRODUÇÃO}

O tratamento de resíduos químicos gerados nos laboratórios das instituições de ensino e pesquisa no Brasil é um assunto cada vez mais discutido entre a comunidade acadêmica ${ }^{1}$. Nas universidades, não são raros os casos em que os alunos de graduação (dos diversos cursos que se utilizam da Química), em suas práticas laboratoriais, não são devidamente instruídos sobre a geração de resíduos e seu devido tratamento antes do descarte. Assim, os resíduos provenientes de sínteses químicas e testes analíticos acabam sendo descartados diretamente no sistema de esgoto sanitário, resultando em contaminação ambiental. Em outros casos, diferentes resíduos são armazenados em um mesmo recipiente sem identificação, o que dificulta sua caracterização ${ }^{1}$, e não são tomadas iniciativas quanto ao seu tratamento e destino final. Felizmente, a crescente preocupação com o meio ambiente tem despertado o interesse de alguns Institutos de Química em criar programas de gerenciamento dos resíduos gerados nos laboratórios de ensino e pesquisa ${ }^{1-3}$, que podem servir de modelo para aqueles que ainda não dispõem destes programas. Dentre as medidas tomadas estão: minimização dos resíduos produzidos, cadastramento e segregação dos diferentes resíduos a serem estocados, tratamento antes da destinação final, e a recuperação daqueles que possam ser reutilizados ${ }^{1-3}$.

Tradicionalmente, sempre que se deseja traçar uma estratégia de síntese em laboratório ou em escala piloto, seja nas universidades ou indústrias, a maior parte dos esforços são concentrados em se obter uma rota sintética que vise minimizar os custos e maximizar o rendimento do produto desejado. Assim, os subprodutos das reações, ou resíduos, só recebem a devida atenção depois de constatados os danos ambientais. Portanto, quando se pretende desenvolver um novo experimento, que envolva substâncias químicas, é fundamental que no seu planejamento sejam avaliadas a toxicidade e a reatividade dos reagentes e de todos os possíveis subprodutos da síntese. Deve-se considerar também, se estes reagentes e subprodutos não atuam como precursores de substâncias potencialmente tóxicas quando expostos no meio ambiente. Desta maneira, é desejável inserir no planejamento os procedimentos de tratamento, descarte ou reutilização dos resíduos gerados.

\footnotetext{
*e-mail: mdepaoli@iqm.unicamp.br
}

Nos últimos 25 anos uma nova classe de polímeros, chamados polímeros intrinsecamente condutores (PIC's), despertou o interesse de vários grupos de pesquisa pelo fato de apresentarem interessantes propriedades elétricas, possibilitando sua utilização em diversas aplicações tecnológicas como diodos emissores de luz, filmes para dissipação de carga elétrica, blindagem eletromagnética, janelas inteligentes, narizes eletrônicos, músculos artificiais, etc ${ }^{4-8}$. Dentre os polímeros condutores, a polianilina (PAni) se destaca pelo fato de apresentar uma boa estabilidade ambiental e ser de fácil obtenção $0^{9,10}$. A polianilina pode ser obtida por oxidação química ou eletroquími$\mathrm{ca}^{11-14}$. Entretanto, a síntese por oxidação química é o método mais utilizado quando se deseja obter grandes quantidades de polianilina, uma vez que a quantidade de produto da síntese não é limitada pela área dos eletrodos ${ }^{6}$. Com o crescente aumento do interesse pela PAni, inclusive o industrial, a síntese por oxidação química é o método mais viável para a sua obtenção em grande escala. Vários agentes oxidantes podem ser utilizados na síntese química da PAni: persulfato de amônio, dicromato de potássio, iodato de potássio ${ }^{14-16}$, sulfato cérico, vanadato de sódio, ferricianeto de potássio ${ }^{14}$, peróxido de hidrogênio ${ }^{14,17} \mathrm{e}$, mais recentemente, peróxido de benzoíla ${ }^{18} \mathrm{em}$ solvente apolar. Dicromato de potássio e persulfato de amônio têm sido os oxidantes mais utilizados na obtenção da PAni em meio aquoso ácido a baixas temperaturas ${ }^{16}$. Entretanto, o uso do $\mathrm{K}_{2} \mathrm{Cr}_{2} \mathrm{O}_{7}$ deve ser evitado uma vez que o $\mathrm{Cr}(\mathrm{VI})$ é classificado como um composto mutagênico e carcinogênico ${ }^{19,20}$, e os resíduos da síntese podem conter o crômio no estado de oxidação VI, além de existir a possibilidade do $\mathrm{Cr}$ (III) ser oxidado à $\mathrm{Cr}(\mathrm{VI})$ no corpo receptor dos resíduos ${ }^{19}$. Por outro lado, o $\left(\mathrm{NH}_{4}\right)_{2} \mathrm{~S}_{2} \mathrm{O}_{8}$ é o agente oxidante mais utilizado na síntese química da $\mathrm{PAni}^{21}$, pois apresenta boa solubilidade em água, conduz a bons rendimentos da PAni e os produtos da sua redução são de fácil tratamento e baixa toxicidade, uma vez que são gerados sais de metais leves e ácidos inorgânicos. A Figura 1 esquematiza a reação de polimerização da anilina com persulfato de amônio, em solução de um ácido monoprótico genérico do tipo HA.

Existem muitas variações na síntese da PAni. Os principais parâmetros que afetam a qualidade do produto obtido e, conseqüentemente, os tipos de resíduos gerados são: natureza e $\mathrm{pH}$ do meio, concentração do agente oxidante, tempo de reação e temperatura ${ }^{14}$. Segundo alguns autores, a primeira etapa de polimerização envolve a oxidação da anilina formando o cátion radical, sendo as etapas pos- 


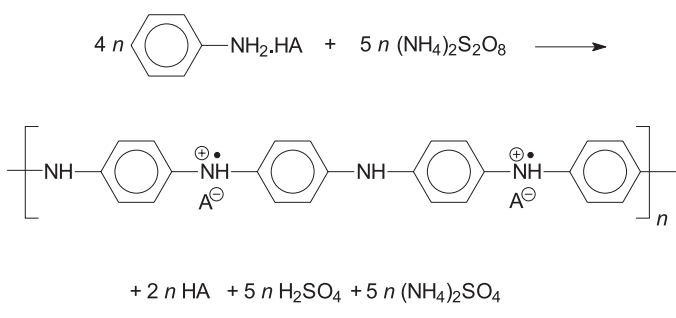

Figura 1. Oxidação da anilina com persulfato de amônio produzindo polianilina dopada com um ácido genérico $H A$

teriores, de acoplamento, fortemente dependentes do $\mathrm{pH}^{12}$. Em condições ácidas prevalece o acoplamento cabeça-cauda, que favorece a formação do dímero predominante no processo de polimerização da PAni condutora, $p$-aminodifenilamina (ADPA) $)^{22,23}$. À medida que o $\mathrm{pH}$ do sistema aumenta, tornando-se neutro, observam-se evidências da formação de ligações $\mathrm{N}-\mathrm{N}$, sugerindo o acoplamento cabeça-cabeça ${ }^{23}$. De fato, compostos do tipo hidrazobenzeno e azobenzeno podem ser obtidos da oxidação da anilina em meio básico ${ }^{24}$. Em pH fortemente ácido, produtos associados ao acoplamento cauda-cauda, como a benzidina, são observados e a sua proporção em relação ao ADPA tende a aumentar com a diminuição do $\mathrm{pH}^{14,25,26}$. Assim, podem estar presentes como subprodutos da síntese da PAni espécies como benzidina, hidrazobenzeno, azobenzeno e outros produtos da hidrólise e degradação oxidativa da PAni como benzoquinona e hidroquinona ${ }^{11,12,27-30}$. Além destes subprodutos, resíduos de anilina não polimerizada também estarão presentes ${ }^{31}$. A Figura 2 esquematiza os possíveis subprodutos da síntese da PAni.

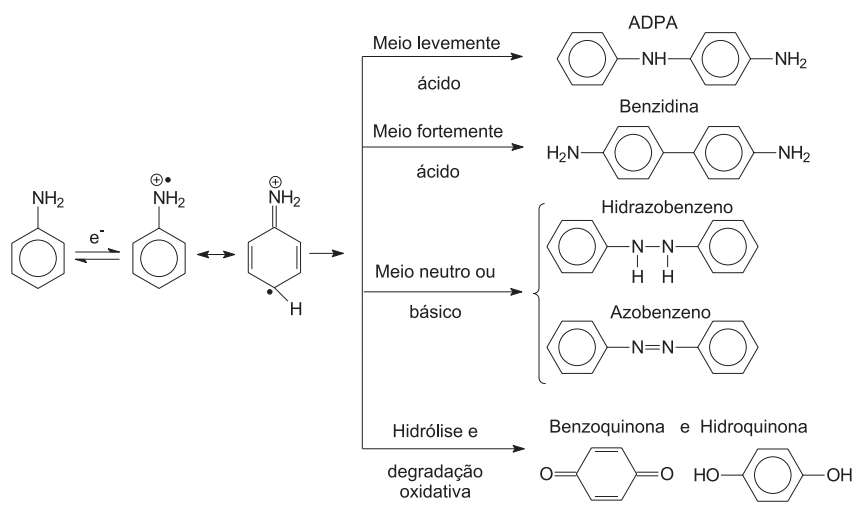

Figura 2. Representação do acoplamento oxidativo da anilina. O ADPA é o dímero precursor da PAni. As outras estruturas são subprodutos da síntese e sua quantidade depende da natureza do meio reacional

Dos subprodutos gerados no resíduo da síntese da PAni com $\left(\mathrm{NH}_{4}\right)_{2} \mathrm{~S}_{2} \mathrm{O}_{8}$, a matéria orgânica, constituída essencialmente por aminas aromáticas, é a que pode acarretar maiores problemas ambientais e de saúde pública. As aminas aromáticas representam uma das mais importantes classes de substâncias químicas no que diz respeito ao meio ambiente e atividades industriais ${ }^{32}$. Já está estabelecido por vários estudos que as aminas aromáticas, que são usadas como intermediários em indústrias químicas e farmacêuticas, mostraram atividade cancerígena em animais e, conseqüentemente, são suspeitas de serem possíveis carcinógenos para os seres humanos. Aminas aromáticas como 2-naftilamina, benzidina e 4aminodifenil já constam nas listas das substâncias comprovadamente carcinogênicas em seres humanos ${ }^{32,33}$. Portanto, deve-se tomar todas as medidas de segurança necessárias quando se manusear aminas aromáticas pois, mesmo que estas não sejam comprovadamente carcinogênicas, podem atuar como precursores de outras que sejam. Como exemplo, Oh e colaboradores ${ }^{34}$ investigaram várias tintas e corantes obtidos a partir de matéria prima isenta de qualquer amina aromática considerada carcinogênica. Estas, quando submetidas a ambientes redutores, produziram 2-naftilamina, 2,4-toluenodiamina, 4,4'-diaminodifenilmetano, 4-aminodifenil e benzidina, aminas aromáticas conhecidas como carcinógenos.

Dentre os possíveis subprodutos da síntese da PAni, a benzidina é o que deve ocorrer em maior proporção uma vez que a reação ocorre em meio ácido, e este ambiente favorece a sua formação como subproduto $^{35}$. Segundo Choudhary ${ }^{36}$, a benzidina é conhecida como uma substância cristalina, sintética, originalmente produzida para ser usada na fabricação de corantes de tecidos, papel, couro e outros materiais. A exposição à benzidina pode ocasionar o surgimento de câncer na bexiga, no fígado e nas vias biliares em seres humanos. O contato com a pele provoca irritação, dermatite e outros sintomas como diminuição da massa do fígado e dos rins, aumento do baço, inchaço do fígado e sangue na urina. A benzoquinona e a hidroquinona também podem ocorrer como subprodutos da hidrólise na síntese da PAni. Ambos são identificados como metabólitos do benzeno no corpo humano, e são suspeitos de provocarem mutações em células humanas, induzindo o surgimento de câncer $^{37}$. Além destes, anilina nãopolimerizada também estará presente no resíduo e a quantidade dependerá da maneira como a síntese foi conduzida ${ }^{31}$. Os principais efeitos tóxicos da anilina, bem como de seus metabólitos, estão associados à indução de metemoglobinemia (redução da capacidade do sangue em transportar oxigênio), hemólise e anemia hemolítica, intoxicação do baço e câncer ${ }^{38,39}$. A ATSDR ("Agency for Toxic Substance and Disease Registry, USA" $)^{40}$ em documento eletrônico classifica a anilina como substância tóxica, mas sem atividade carcinogênica em seres humanos, seguindo a classificação disponibilizada pela IARC-WHO ("International Agency for Research on Câncer - World Health Organization" ${ }^{41}$. Embora a atividade direta da anilina como carcinógeno continue sendo motivo de controvérsia, várias substâncias que causam intoxicações em órgãos internos do corpo humano têm sua estrutura relacionada com a anilina ${ }^{42}$. Por causa disto, vários estudos têm sido realizados com o intuito de entender melhor a resposta de organismos vivos quando expostos a essas aminas aromáticas e até que ponto seus metabólitos podem atuar como intermediários ativos com capacidade de se ligarem a macromoléculas críticas como o DNA $^{33,38,42-46}$. Em uma nota publicada pela NIOSH ("National Institute for Occupational Safety and Health, USA") ${ }^{47}$ alertando sobre o aumento na incidência de tumores na bexiga, em trabalhadores expostos à anilina e $o$-toluidina, há a recomendação que se tomem todas as medidas de segurança necessárias para se evitar o contato destas substâncias com a pele e vias respiratórias. Na síntese da PAni, dependendo das condições de síntese e concentração dos reagentes, pode-se obter resíduos de coloração bastante escura ${ }^{31}$ evidenciando a presença de subprodutos orgânicos conjugados, como oligômeros da anilina. Além do caráter nocivo já citado, o fato deste resíduo ser constituído essencialmente de matéria orgânica torna-o ainda mais prejudicial aos mananciais aquáticos que abrigam formas de vida aeróbica.

Com base nesta breve abordagem sobre a toxicidade dos reagentes e subprodutos oriundos da síntese química da PAni, fica clara a necessidade de se fazer um tratamento adequado dos resíduos gerados. Além disso, antes do tratamento final, um outro aspecto importante que deve ser levado em consideração é a reutilização do filtrado em novas sínteses. Como os subprodutos são constituídos de oligômeros da anilina e sais inorgânicos (Figura 1), a correção do $\mathrm{pH}$ pela adição do ácido dopante e, se necessário, uma pequena diluição, tornará o filtrado apto a ser reutilizado como meio reacional. A presença de sais inorgânicos aumenta a força iônica do meio, o que pode re- 
sultar em melhor rendimento e condutividade ${ }^{48}$ e a presença do ácido inorgânico obtido como subproduto não irá afetar o produto final (PAni), desde que o ácido dopante esteja em maior quantidade estequiométrica. Desta forma, o volume de resíduo gerado em sínteses consecutivas será consideravelmente diminuído.

Este trabalho tem por objetivo oferecer uma rota de tratamento dos resíduos da síntese da polianilina em escala pré-piloto, uma vez que o interesse por este polímero tem crescido muito nos últimos anos e a sua síntese nesta escala é praticada em diversas instituições de pesquisa no Brasil.

\section{PARTE EXPERIMENTAL}

\section{Síntese}

A PAni foi sintetizada em um reator de $12 \mathrm{~L}$, de vidro encamisado, contendo anilina (Bann Química, Paulínia) 0,1 mol L-1 em solução de $\mathrm{HCl}$ (Solvay, Ribeirão Pires) $1,0 \mathrm{~mol} \mathrm{~L}^{-1}$ e $\mathrm{NaCl}$ (Ecibra, Santo Amaro) 3,0 mol L-1. O agente oxidante, $\left(\mathrm{NH}_{4}\right)_{2} \mathrm{~S}_{2} \mathrm{O}_{8}$ (Synth, Diadema) 1,5 mol L-1, em solução aquosa de $\mathrm{HCl} 1 \mathrm{~mol} \mathrm{~L}^{-1 /} \mathrm{NaCl}$ $3 \mathrm{~mol} \mathrm{~L}^{-1}$ foi adicionado por gotejamento através de um funil de adição durante $1 \mathrm{~h}$. Em algumas sínteses foi utilizado o $\mathrm{CoSO}_{4}(\mathrm{Carlo}$ Erba 99\%, Milano) como catalisador. A temperatura da camisa de refrigeração do reator foi mantida em torno de $-5^{\circ} \mathrm{C}$ e o tempo total de síntese foi de $2 \mathrm{~h}$. A solução resultante foi filtrada ${ }^{31}$. Armazenouse o filtrado em um frasco de polipropileno para tratamento e posterior descarte. Em seguida, lavou-se o polímero com água destilada. A solução incolor, resultante desta etapa, foi neutralizada com carbonato de sódio e descartada no esgoto.

\section{Determinação do teor de carbono orgânico total (TOC) no resíduo da síntese}

Prepararam-se duas alíquotas do resíduo da síntese para a análise de TOC. O pH das amostras foi ajustado entre 2,0 e 3,0, adicionandose gotas de uma solução saturada de $\mathrm{NaOH}$. Em seguida, realizou-se purga de $\mathrm{CO}_{2}$ borbulhando argônio por 10 min nas amostras, que posteriormente foram injetadas em um analisador de carbono orgânico total (Total TOC-5000, Shimadzu), obtendo-se um valor médio de concentração de carbono orgânico para o resíduo da síntese.

Uso de carvão ativado para a adsorção dos compostos orgânicos e do $\mathrm{Co}^{2+}$ presentes no resíduo

A relação carvão ativado/volume de resíduo foi otimizada através da variação dos parâmetros: quantidade de carvão, tempo de adsorção e agitação. Utilizou-se carvão marca Norit (custo em Março de 2003; R\$ 158,00 por embalagem de $30 \mathrm{~kg}$ ). A variação na absorbância da matéria orgânica foi monitorada por espectrofotometria (espectrofotômetro UV-Vis Diode Array, 8452A HP), na faixa de 230 a $550 \mathrm{~nm}$ e a presença do $\mathrm{Co}^{2+}$ no resíduo da síntese (proveniente do catalisador), antes e depois do tratamento, foi verificada por Fluorescência de Raios-x (Spectrace 5000, Tracor), sob as seguintes condições de irradiação: voltagem e corrente do tubo, respectivamente: $30 \mathrm{kV}$ e $0,02 \mathrm{~mA}$, atmosfera: argônio, filtro: Rh 0,05 mm, tempo: $100 \mathrm{~s}$.

\section{RESULTADOS}

\section{Rendimento da síntese}

Através do processo descrito obteve-se PAni condutora (sal esmeraldina), na forma de grânulos finos de cor verde. Consideran- do-se o polímero obtido como sendo constituído apenas por PAni( $\mathrm{HCl}$ ) 50\% dopada, calculou-se um rendimento de $\sim 95 \%$.

\section{Determinação do TOC no resíduo da síntese e uso de carvão ativo para a adsorção das substâncias tóxicas presentes no resíduo}

O resíduo da síntese apresentou cerca de $484 \mathrm{mg} \mathrm{L}^{-1}$ de TOC. Apesar das legislações federais e estaduais não estipularem diretamente limites de TOC em resíduos industriais, a Resolução CONAMA N ${ }^{\circ}$ 20/86 estabelece que os efluentes não devem conferir ao corpo receptor características diferentes daquelas usadas na sua classificação ${ }^{49}$. Logo, esse valor de TOC foi considerado elevado para o descarte dos resíduos em esgoto, por tratar-se de um efluente constituído por compostos aromáticos e de elevada toxidez.

Como resultado da otimização do procedimento foram utilizados $5 \mathrm{~g}$ de carvão ativado para cada $50 \mathrm{~mL}$ de resíduo ${ }^{50}$. A Figura 3 mostra o espectro, obtido na região do UV-Vis, do resíduo da síntese da PAni, antes e após o tratamento. Os resultados mostram que os compostos orgânicos, responsáveis pela forte absorção em $292 \mathrm{~nm}$, foram adsorvidos completamente pelo carvão ativado após $17 \mathrm{~h}$ de tratamento, independentemente da agitação do sistema. A reação de adsorção dos compostos orgânicos mostrou-se irreversível. A Figura 4 mostra os espectros de fluorescência de raios-x obtidos para o resíduo da síntese da PAni (a) antes e (b) depois do tratamento. Os picos atribuídos ao $\mathrm{Co}^{2+}$ não são observados no espectro após o tratamento do resíduo com carvão ativado. Isto significa que o $\mathrm{Co}^{2+}$ também foi extraído nesta etapa do tratamento. Isto pode ser explicado pelo fato do cobalto, sendo um metal pesado, ser capaz de formar complexos estáveis com as aminas aromáticas presentes no resíduo e, desta forma, também ser adsorvido com os compostos orgânicos. Esta é uma das vantagens do método utilizado, pois a separação do $\mathrm{Co}^{2+}$ da fração aquosa deveria ser realizada através da sua precipitação na forma de hidróxido, o que não foi necessário.

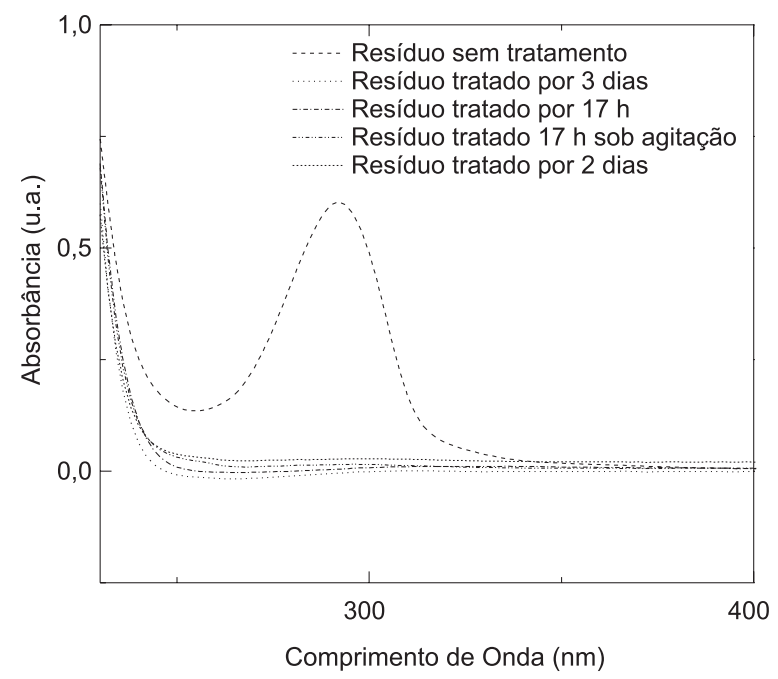

Figura 3. Espectros na região do UV-Vis do resíduo da síntese de PAni antes e depois do tratamento

\section{Destinação final dos resíduos da síntese após tratamento}

Após a adsorção dos compostos orgânicos em carvão ativo, este foi enviado para a incineração em um equipamento contendo lavador para gases, devido à possibilidade de formação de espécies tóxicas por combustão incompleta ${ }^{51}$. A fração líquida aquosa foi neutralizada com carbonato de sódio comercial e descartada no esgoto. 


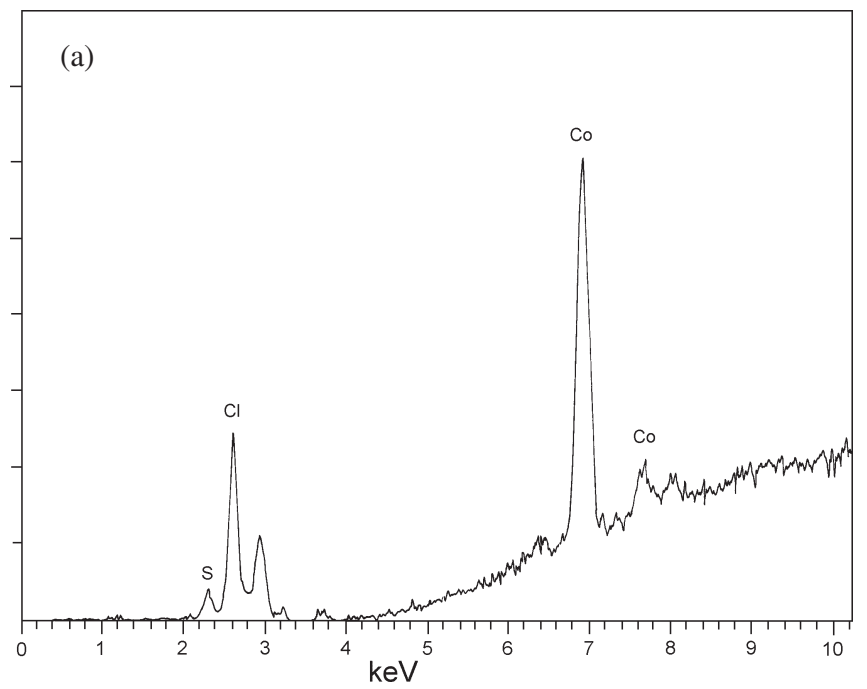

(b)

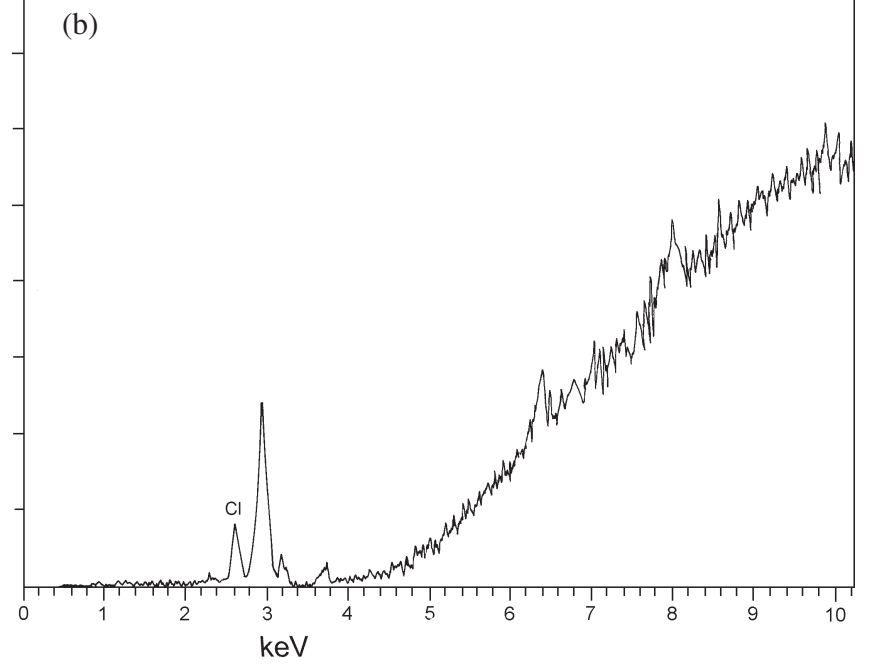

Figura 4. Espectros de fluorescência de raios-x obtidos para o resíduo da sintese da PAni antes (a) e depois do tratamento (b)

A vantagem de incinerar o carvão ao invés do resíduo aquoso é um fator financeiro e ambiental. Trata-se de um resíduo com grande proporção de água e isto eleva os custos de transporte e de incineração. O carvão é um combustível natural enquanto a água necessita ser misturada a solventes.

\section{CONCLUSÃO}

A adsorção em carvão ativado das substâncias tóxicas presentes no resíduo da síntese química da PAni mostrou-se eficiente para tratar os resíduos produzidos em nosso laboratório. Como vantagens do método empregado destacam-se: simplicidade, baixo custo (para cada batelada com $12 \mathrm{~L}$ de resíduo gasta-se $\mathrm{R} \$ 6,30$ para o tratamento) e facilitação do processo de incineração do resíduo, devido à minimização de volume e natureza físico-química do material adsorvente. No caso de impossibilidade de incinerar o resíduo em equipamentos adequados, estes podem ser dispostos em aterros para resíduos químicos e, nesta situação, a minimização do volume de resíduo também é uma vantagem. Outras maneiras de tratar o resíduo da síntese química da PAni também foram estudadas, porém não foram obtidos bons resultados. Como exemplo, é relevante citar a utilização de processos de degradação, empregando radiação UV ou agentes oxidantes (peróxido de hidrogênio e $\mathrm{FeCl}_{2}$ ) juntamente com a radiação UV, segundo metodologias de decomposição existentes para a anilina ${ }^{51}$. Os testes realizados mostraram que esses métodos não podem ser aplicados diretamente sobre os resíduos em questão.

\section{AGRADECIMENTOS}

R. A. de Sousa agradece a bolsa de Iniciação Científica do SAE/ Unicamp. Os autores agradecem o apoio financeiro do programa PRONEx/CNPq e ao Prof. Dr. W. F. Jardim por viabilizar as análises de TOC em seu laboratório. O. A. Araújo agradece à Universidade Estadual de Goiás pela licença concedida.

\section{REFERÊNCIAS}

1. Jardim, W. F.; Quim. Nova 1998, 21, 671.

2. Cunha, C. J.: Quim. Nova 2001, 24, 424.

3. Amaral, S. T.; Machado, P. F. L.; Peralba, C. R.; Câmara, M. R.; Santos, T.; Berleze, A. L.; Falcão, H. L.; Martinelli, M.; Gonçalves R. S.; Oliveira E. R.; Brasil, J. L.; Araújo, M. A.; Borges, A. C. A.; Quim. Nova 2001, $24,419$.

4. Maia, D. J.; De Paoli, M-A.; Alves, O. L.; Zarbin, A. J. G.; Neves, S.; Quim. Nova 2000, 23, 204

5. Rezende, M. C.; Faez, R.; Martin, I. M.; De Paoli, M-A.; Polímeros; Ciênc. Tecnol. 2000, 10, 130.

6. Kumar, D.; Sharma, R. C.; Eur. Polym. J. 1998, 34, 1053

7. Malinauskas, A.; Polymer 2001 42, 3957.

8. Bhattacharya, A.; De, A.; Prog. Solid State Chem. 1996, 24, 141.

9. Tang, J.; Jing, X.; Wang, B.; Wang, F.; Synth. Met. 1988, 24, 231.

10. Wang, Y.; Rubner, M. F.; Synth. Met. 1992, 47, 255

11. Gospodinova, N.; Terlemezyan, L.; Prog. Polym. Sci. 1998, 23, 1443.

12. Kang, E. T.; Neoh, K. G.; Tan, K. L.; Prog. Polym. Sci. 1998, 23, 277.

13. Anand, J.; Palaniappan, S.; Sathyanarayana, D. N.; Prog. Polym. Sci. 1998, $23,993$.

14. Syed, A. A.; Dinesan, M. K.; Talanta 1991, 38, 815.

15. Rodrigues, M. A.; De Paoli, M-A.; Synth. Met.1991, 41-43, 2957.

16. Adams, P. N.; Abell, L.; Middleton, A.; Monkman, A. P.; Synth. Met. 1997, $84,61$.

17. Sun, Z.; Geng, Y.; Li, J.; Jing, X.; Wang, F.; Synth. Met. 1997, 84, 99.

18. Rao, P. S.; Sathyanarayana, D. N.; Palaniappan, S.; Macromolecules 2002, $35,4988$.

19. Jordão, C. P.; Silva, A. C.; Pereira, J. L.; Brune, W.; Quim. Nova 1999, $22,47$.

20. Ferreira, A. D. Q.; Quim. Nova 2002, 25, 572.

21. Stejskal, J.; Gilbert, R. G.; Pure Appl. Chem. 2002, 74, 857.

22. Mohilner, D. M.; Adams, R. N.; Argersinger Jr., W. J.; J. Am. Chem. Soc. 1962, 84, 3618 .

23. Ohsaka, T.; Ohnuki, Y.; Oyama, N.; J. Electroanal. Chem. 1984, 161, 399.

24. Konaka, R.; Kuruma, K.; Terabe, S.; J. Am. Chem. Soc. 1968, 90, 1801.

25. Stejskal, J.; Kratochvíl, P.; Spórková, M.; Polymer 1995, 36, 4135.

26. Bremer, L. G. B.; Vergong, M. W. C. G.; Webers, M. A. M.; van Doorn, M. A. M. M.; Synth. Met. 1997, 84, 355.

27. Cases, F.; Huerta, F.; Garcés, P.; Morallón, E.; Vázquez, J. L.; J. Electroanal. Chem. 2001, 501, 186.

28. Chen, W-C.; Wen, T-C.; Hu, C-C.; Gopalan, A.; Electrochim. Acta 2002, $47,1305$.

29. Chen, W-C.; Wen, T-C.; Gopalan, A.; Synth. Met. 2002, 128, 179

30. Ahmed, S. M.; Eur. Polym. J. 2002, 38, 1151.

31. Freitas, P. S.; Tese de Doutorado, Universidade Estadual de Campinas, Brasil, 2000.

32. Benigni, R.; Passerini, L.; Mutat. Res. 2002, 511, 191.

33. McManus, M. E.; Clin. Exp. Pharmacol. Physiol. 1989, 16, 491.

34. Oh, S. W.; Kang, M. N.; Cho, C. W.; Lee, M. W.; Dyes Pigm. 1997, 33, 119.

35. Bacon, J.; Adams, R. N.; J. Am. Chem. Soc. 1968, 90, 6596.

36. Choudhary, G.; Chemosphere 1996, 23, 267.

37. Nakayama, A.; Koyoshi, S.; Morisawa, S.; Yagi, T.; Mutat. Res. 2000, 470, 147.

38. Cerniglia, C. E.; Freeman, J. P.; Baalen, C. V.; Arch. Microbiol. 1981, 130, 272.

39. Khan, M. F.; Kaphalia, B. S.; Boor, P. J.; Ansari, G. A. S.; Arch. Environ. Contam. Toxicol. 1993, 24, 368. 
40. www.atsdr.cdc.gov/mhmi.html\#MMG, acessada em Novembro 2002.

41. www.iarc.fr/, acessada em Novembro 2002.

42. Bus, J. S.; Popp, J. A.; Food Chem. Toxicol. 1987, 25, 619.

43. Abram, F. S. H.; Sims, I. R.; Water Res. 1982, 16, 1309.

44. Gersich, F. M.; Milazzo, D. P.; Bull. Environ. Contam. Toxicol. 1988, 40, 1.

45. Westmoreland, C.; Gatehouse, D. G.; Carcinogenesis 1991, 12, 1057.

46. Groth, G.; Schreeb, K.; Herdt, V.; Freundt, K. J.; Bull. Environ. Contam. Toxicol. 1993, 50, 878 .
47. NIOSH alert; Am. Ind. Hyg. Assoc. J. 1991, 52, A-260.

48. Gazotti, W. A.; De Paoli, M-A.; Synth. Met. 1996, 80, 263.

49. www.mma.gov.br/port/conama/index.html., acessada em Novembro 2002.

50. Sousa, R. A.; Freitas, P. S.; De Paoli, M-A.; Resumos da $22^{a}$ Reunião Anual da Sociedade Brasileira de Química, Poços de Caldas, Brasil, 1999.

51. Verschueren, K.; Handbook of Environmental Data on Organic Chemicals, Van Nostrand, Reinhold: New York, $3^{\text {rd }}$ ed, 1996, p. 197-201. 